\title{
Effect of a biogenic silica and green-tea- flavonoids-based mechanocomposite on Fragaria $\times$ ananassa Duch. leaf anatomy in in vitro conditions
}

\author{
Elena Ambros ${ }^{1, *}$, Victoria Batrakova ${ }^{2}$, Alexander Krasnikov ${ }^{1}$, Yulianna Zaytseva ${ }^{1}$, Elena \\ Trofimova ${ }^{3}$, and Tatyana Novikova ${ }^{1}$ \\ ${ }^{1}$ Central Siberian Botanical Garden, Siberian Branch of the Russian Academy of Sciences, \\ Zolotodolinskaya st., 101, 630090 Novosibirsk, Russian Federation \\ ${ }^{2}$ Novosibirsk State Pedagogical University, Vilyuyskaya st., 18, 630126, Novosibirsk, Russian \\ Federation \\ ${ }^{3}$ Institute of Solid State Chemistry and Mechanochemistry Siberian Branch of the Russian Academy \\ of Sciences, Kutateladze st., 18, 630128 Novosibirsk, Russian Federation
}

\begin{abstract}
For the first time light and scanning electron microscopy have been to reveal changes in the anatomical structure of leaf blades of Fragaria $\times$ ananassa Duch. regenerants cultivated in nutrient media supplemented with biogenic silica and green-tea-flavonoids-based mechanocomposite. An increase in the density of stomata per unit area of the leaf, size of the stomatal gaps, thickness of the epidermis and mesophyll have been noted. The revealed changes in the leaf blade structure under mechanocomposite treatment contribute to the further successful acclimatization of regenerants to ex vitro conditions.
\end{abstract}

\section{Introduction}

Strawberry (Fragaria $\times$ ananassa Duch.) is the most widely consumed berries throughout the world. F. ananassa is traditionally propagated vegetatively by rooted runners. However this method is not suitable for production of strawberry cultivars due to accumulation and transfer of viral, fungal and bacterial diseases from mother plants. The use of clonal micropropagation allows to obtain not only a healthy planting material, but to increase significantly the rate of commercial reproduction of $F$. ananassa cultivars. Despite the effectiveness of the technology, in vitro cultivation causes a number of anomalies that manifest at the level of functional morphophysiological features of the regenerant leaf blades, such as underdevelopment of the epidermis and photosynthetic tissues, including the palisade parenchyma, vascular bundles, and formation of an abnormal stomatal apparatus with a small number of stomata per $1 \mathrm{~mm}^{2}$ of the leaf surface [1]. All these changes are due to in vitro culture conditions characterized by high relative humidity, low gas exchange, presence of exogenous carbohydrates and low rate of $\mathrm{CO}_{2}$ absorption [2]. As

*Corresponding author: $\underline{\text { ambros_ev@mail.ru }}$ 
a result, when transferring microclones to ex vitro conditions, decrease of survival rate leading to reduce of technology efficiency is possible. A number of studies have shown that in vitro application of silicon compounds improves photosynthetic capacity of plants, positively affects the anatomical and morphological parameters of the leaves [3, 4]. Siliconcontaining preparations obtained from renewable plant raw materials by mechanochemical methods arouse considerable interest. The advantage of mechanochemical technology of raw materials processing is extraction of valuable compounds with the least impact on the environment, without additional costs of thermal energy and chemical reagents [5]. Mechanocomposites of this type have increased solubility, retain their natural composition and therefore are most effectively absorbed by plants, which determines the prospects of their use in biotechnologies as new biologically active compounds with growth regulating activity and at the same time, safe for human health and environment [6,7]. We suppose that application of the mechnocomposite studied may provide opportunities for improvement of physiological adaptation to the transferring stress during ex vitro acclimatization of plantlets. Therefore, the objectives of the present study were (i) to analyze the anatomical features of regenerant leaves under the influence of a mechanocomposite based on biogenic silicium dioxide and flavonoids of plant origin during the rooting stage in in vitro conditions and (ii) to optimize the protocol of clonal micropropagation for strawberry large-scale production using the mechanocomposite.

\section{Materials and methods}

\subsection{Characterization of mechanocomposite}

A mechanocomposite (MC) was produced from rice husks (Oryza sativa, cv 'Liman,' Krasnodar Krai, Russia) and green tea (Camellia sinensis L.) (Krasnodar Krai, Russia) at the Institute of Solid State Chemistry and Mechanochemistry of the Siberian Branch of the Russian Academy of Sciences (Novosibirsk, Russia) by mechanical activation in an RM-20 roller mill with water cooling. The rotation speed was $1000 \mathrm{rpm}$. The material residence time in the active zone was 40-60 s [8]. Rice husk contains high levels of biogenic silica. The leaves of $C$. sinensis contain phenolic compounds with antioxidant properties. These compounds have chelating functional groups and can increase significantly the solubility of silica.

\subsection{Plant material and culture conditions}

The anatomical structure of micropropagated plantlet leaf blades of two strawberry cultivars, 'Alpha' and 'Solnechnaya polyanka', under the influence of mechanocomposite during the rooting stage in in vitro conditions was studied. Microshoots $(1.0-1.5 \mathrm{~cm})$ with 2-3 leaves were inoculated on Gamborg-Eveleg's basal salt medium - $\mathrm{B}_{5}$ [9] supplemented with $20 \mathrm{~g} \mathrm{~L}^{-1}$ sucrose, $6 \mathrm{~g} \mathrm{~L}^{-1}$ Bactoagar (PanReac $®$, Spain) and different concentrations of MC (2.5, 5.0 and $\left.10.0 \mathrm{mg} \mathrm{L}^{-1}\right)$ for one passage of $8 \mathrm{wk}$. MC-free $\mathrm{B}_{5}$ was used as control. The $\mathrm{pH}$ was adjusted to 5.5 before autoclaving $\left(121^{\circ} \mathrm{C}, 2.1 \mathrm{~atm}\right.$ for $20 \mathrm{~min}$ ), and mechanocopmosite was added to the medium before autoclaving. The cultures were maintained in culture jars $\left(15 \mathrm{~mL}\right.$ medium per vessel) at $23 \pm 2{ }^{\circ} \mathrm{C}$ with a 16 -h photoperiod with $40 \mu \mathrm{mol} \mathrm{m} \mathrm{m}^{-2} \mathrm{~s}^{-1}$ of light intensity provided by cool white fluorescent lamps (Philips, Pila, Poland). 


\subsection{Anatomical and stomatographic studies of leaf structure}

The leaf anatomy, stomata number, and size were measured in the fresh plant material after 8 weeks. The second leaf from the apical bud of the shoot was taken for analysis. Sections of 50-60 $\mu \mathrm{m}$ were made using an MC-2 sledge microtome with a TOC-II thermo-cooling table (Tochmedpribor, Kharkiv, Ukraine). The histological analysis was performed using a microscope equipped with an Axioskop-40, an AxioCam MRc5 camera, and AxioVision 4.8 software (Carl Zeiss). Morphometric measurements were conducted in 10 fields of vision for each preparation. Stomatal density was calculated on the abaxial side of the leaf using a Hitachi TM-1000 scanning electron microscope with original software (Hitachi High-Tech., Tokyo, Japan). This allowed biological objects to be investigated without spraying. Sections of the middle part of the leaf $\left(5-7 \mathrm{~mm}^{2}\right)$ from ten randomly selected plantlets of each study group were taken for the analysis. Ten leaves per processing were measured, using one leaf per plantlet. Stomata density was calculated on ten distinct, nonrepeating lines of sight for each leaf. Anatomical features of stomata were determined for 300 randomly selected stomata.

\subsection{Statistical analysis}

Experiments were repeated three times, and 20 microshoots were used for each treatment. To assess the effect of mechanocomposite on the anatomical parameters, data were subjected to analysis of variance (ANOVA) using STATISTICA ${ }^{\text {тм }} 8$ (StatSoft, Inc., Tulsa, OK). Significance between means was tested by Duncan's new multiple range test $(\mathrm{P}=$ $0.05)$. Data are presented as a means $\pm \mathrm{SE}$.

\section{Results and Discussion}

Estimation of stomatal density in in vitro culture showed that this parameter depended on MC concentration in medium and increased significantly up to $60 \%$ in comparison with control (Table 1). According to literature an increase of stomatal density provides a higher absorption of $\mathrm{CO}_{2}$ [10] positively affecting the intensity of photosynthesis [11]. Maximum of stomatal density was observed on medium supplemented with $5 \mathrm{mg} \mathrm{L}^{-1} \mathrm{MC}$ (Fig. a, b). Moreover, statistically significant differences in the morphometric parameters of the stomata were revealed. The ratio of the stomata polar diameter to the equatorial diameter characterizes the degree of their closure.

Table 1. Stomatal density and stomata size of leaf abaxial surfaces of $F$. ananassa plantlets under MC after 8 wk of culture

\begin{tabular}{|c|c|c|c|c|c|}
\hline Cultivar & $\begin{array}{c}\text { MC, } \\
\mathrm{mg} \mathrm{L}^{-1}\end{array}$ & $\begin{array}{c}\text { Stomata } \\
\text { number per } \\
\mathrm{mm}^{2}\end{array}$ & $\begin{array}{c}\text { Polar } \\
\text { diameter } \\
(\mathrm{PD}), \mu \mathrm{m}\end{array}$ & $\begin{array}{c}\text { Equatorial } \\
\text { diameter } \\
(\mathrm{ED}), \mu \mathrm{m}\end{array}$ & PD/ED \\
\hline \multirow{4}{*}{$\begin{array}{c}\text { Solnechnaya } \\
\text { polyanka' }\end{array}$} & 0.0 & $291.75 \pm 16.8^{\mathrm{d}}$ & $20.48 \pm 0.20^{\mathrm{a}}$ & $10.91 \pm 0.13^{\mathrm{b}}$ & $1.93 \pm 0.02^{\mathrm{a}}$ \\
\cline { 2 - 6 } & 2.5 & $312.54 \pm 19.3^{\mathrm{cd}}$ & $15.22 \pm 0.09^{\mathrm{c}}$ & $8.88 \pm 0.06^{\mathrm{c}}$ & $1.74 \pm 0.02^{\mathrm{b}}$ \\
\cline { 2 - 6 } & 5.0 & $469.14 \pm 25.4^{\mathrm{a}}$ & $17.94 \pm 0.17^{\mathrm{b}}$ & $11.20 \pm 0.13^{\mathrm{b}}$ & $1.65 \pm 0.02^{\mathrm{c}}$ \\
\cline { 2 - 6 } & 10.0 & $390.84 \pm 23.1^{\mathrm{b}}$ & $20.44 \pm 0.14^{\mathrm{a}}$ & $13.03 \pm 0.11^{\mathrm{a}}$ & $1.60 \pm 0.02^{\mathrm{c}}$ \\
\hline \multirow{6}{*}{ 'Alpha' } & 0.0 & $281.13 \pm 27.4^{\mathrm{b}}$ & $21.22 \pm 0.14^{\mathrm{a}}$ & $10.56 \pm 0.11^{\mathrm{b}}$ & $2.07 \pm 0.02^{\mathrm{a}}$ \\
\cline { 2 - 6 } & 2.5 & $336.58 \pm 17.1^{\mathrm{a}}$ & $20.61 \pm 0.15^{\mathrm{b}}$ & $11.31 \pm 0.10^{\mathrm{a}}$ & $1.86 \pm 0.02^{\mathrm{b}}$ \\
\cline { 2 - 6 } & 5.0 & $374.92 \pm 38.1^{\mathrm{ab}}$ & $19.93 \pm 0.15^{\mathrm{c}}$ & $11.27 \pm 0.11^{\mathrm{a}}$ & $1.83 \pm 0.02^{\mathrm{b}}$ \\
\cline { 2 - 6 } & 10.0 & $364.52 \pm 38.5^{\mathrm{a}}$ & $15.13 \pm 0.14^{\mathrm{d}}$ & $8.20 \pm 0.14^{\mathrm{c}}$ & $1.86 \pm 0.02^{\mathrm{b}}$ \\
\hline
\end{tabular}

Means followed by the same letter are not significantly different $(P=0.05)$ 
In vitro stomatal closure results in a low level of gas exchange and oxidative stress [12], which leads to chlorophyll destruction and emergence of vitrified shoots due to low conductivity of gas and water [13].The largest ratio of the polar stomata diameter to the equatorial one was noted in the control plants (1.93 and 2.07, depending on the genotype), the smallest in the variants of media with $\mathrm{MC}$ (from 1.65 to 1.86, depending on the genotype). Thus, the addition of MC in the base medium resulted in the formation of stomata with a smaller diameter and a high stomatal density. Such changes in the leaf structural and functional organization under $\mathrm{MC}$ contribute to an increase in the adaptability of regenerants to conditions with low humidity and intensive lighting during the plantlet acclimatization to ex vitro conditions [14].

a)

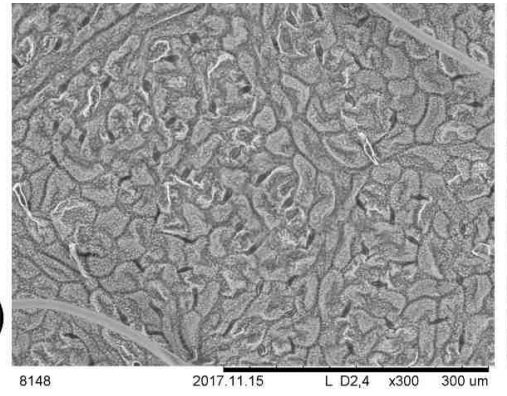

c)

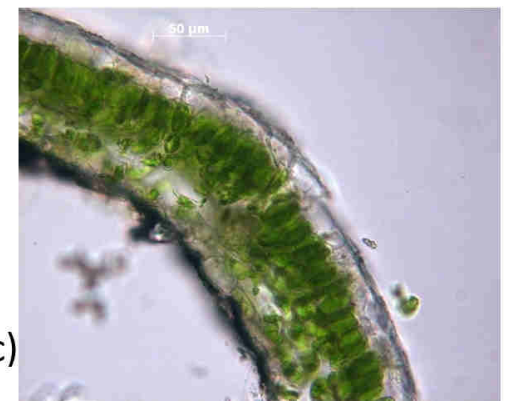

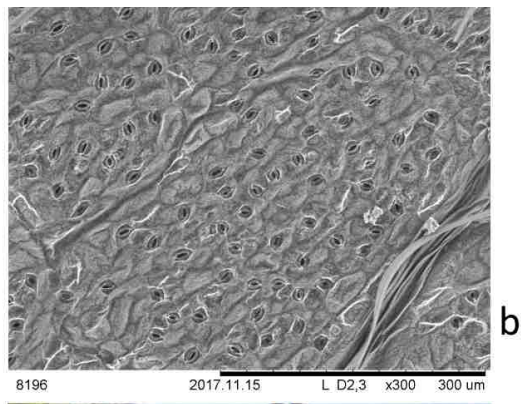

b)

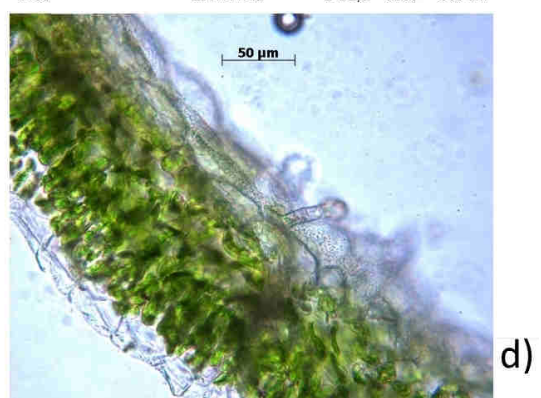

Fig. Leaf blade anatomy characteristics of $F$. ananassa plantlets after 8 wk of culture ('Alpha'): a) stomata on hormone-free $\mathrm{B}_{5}$ medium; b) stomata on medium supplemented with $5 \mathrm{mg} \mathrm{L}^{-1} \mathrm{MC}$; c) transverse section of leaf blade on hormone-free $\mathrm{B}_{5}$ medium; $\mathrm{d}$ ) transverse section of leaf blade on medium supplemented with $10 \mathrm{mg} \mathrm{L}^{-1} \mathrm{MC}$.

Comparative analysis of the anatomical structure of leaf blades of regenerants cultivated on media with $\mathrm{MC}$ revealed that the thickness of the adaxial epidermis increased reliably by $20-30 \%(P<0.05)$ under MC treatment in comparison with the control (Table 2). The thickness of the abaxial epidermis of 'Alfa' cultivar was also higher than in control by 30$40 \%$ when MC was added to the base medium at different concentrations $\left(2.5-10.0 \mathrm{mg} \mathrm{L}^{-1}\right)$. Statistically significant differences in abaxial epidermis thickness of 'Solnechnaya polyanka' were obtained on media supplemented with only $5.0 \mathrm{mg} \mathrm{L}^{-1} \mathrm{MC}$ (up to $\left.10 \%\right)(P$ $<0.05)$. In the presence of all the tested concentrations of MC $\left(2.5-10.0 \mathrm{mg} \mathrm{L}^{-1}\right)$, significant differences in the total mesophyll thickness (up to 30\%) were noted in 'Alpha' cultivar (Fig. c, d). The established differences were due to the high thickness levels of both the spongy and palisade parenchymas. Statistically significant differences in abaxial epidermis thickness as well as mesophyll thickness of 'Solnechnaya polyanka' were obtained on media supplemented with only $5.0 \mathrm{mg} \mathrm{L}^{-1} \mathrm{MC}$ (up to $\left.10 \%\right)(P<0.05$ ).

Table 2. Effect of MC on the thickness of leaf tissues of $F$. ananassa plantlets after 8 wk of culture 


\begin{tabular}{|c|c|c|c|c|c|c|}
\hline \multirow[t]{2}{*}{ Cultivar } & \multirow{2}{*}{$\begin{array}{l}\mathrm{MC}, \\
\mathrm{mg}^{-1} \\
\mathrm{~L}^{-1}\end{array}$} & \multicolumn{5}{|c|}{ Thickness, $\mu \mathrm{m}$} \\
\hline & & $\begin{array}{c}\text { adaxial } \\
\text { epidermis }\end{array}$ & $\begin{array}{c}\text { abaxial } \\
\text { epidermis }\end{array}$ & mesophyll & $\begin{array}{c}\text { palisade } \\
\text { parenchyma }\end{array}$ & $\begin{array}{c}\text { spongy } \\
\text { parenchyma }\end{array}$ \\
\hline \multirow{4}{*}{$\begin{array}{c}\text { 'Solnechnaya } \\
\text { polyanka' }\end{array}$} & 0.0 & $18.2 \pm 0.24^{\mathrm{c}}$ & $21.6 \pm 0.21^{b}$ & $103.5 \pm 0.67^{b}$ & $49.9 \pm 0.24^{\mathrm{c}}$ & $53.6 \pm 0.65^{\mathrm{a}}$ \\
\hline & 2.5 & $20.1 \pm 0.29^{b}$ & $21.9 \pm 0.16^{b}$ & $107.9 \pm 0.89^{\mathrm{ab}}$ & $53.1 \pm 0.48^{b}$ & $54.9 \pm 0.51^{\mathrm{a}}$ \\
\hline & 5.0 & $20.9 \pm 0.20^{b}$ & $23.3 \pm 0.15^{\mathrm{a}}$ & $113.4 \pm 1.30^{\mathrm{a}}$ & $56.7 \pm 0.48^{\mathrm{a}}$ & $56.8 \pm 0.99^{\mathrm{a}}$ \\
\hline & 10.0 & $22.1 \pm 0.21^{\mathrm{a}}$ & $22.3 \pm 0.25^{\mathrm{ab}}$ & $107.2 \pm 2.43^{b}$ & $52.5 \pm 1.02^{\mathrm{b}}$ & $54.7 \pm 1.85^{\mathrm{a}}$ \\
\hline \multirow[t]{4}{*}{ 'Alpha' } & 0.0 & $15.8 \pm 0.31^{b}$ & $16.3 \pm 0.44^{\mathrm{c}}$ & $71.6 \pm 1.83^{\mathrm{c}}$ & $36.2 \pm 1.12^{\mathrm{c}}$ & $35.4 \pm 0.98^{\mathrm{d}}$ \\
\hline & 2.5 & $20.6 \pm 0.62^{\mathrm{a}}$ & $23.0 \pm 0.63^{\mathrm{a}}$ & $90.2 \pm 1.67^{\mathrm{a}}$ & $47.2 \pm 1.19^{\mathrm{a}}$ & $42.9 \pm 0.63^{\mathrm{bc}}$ \\
\hline & 5.0 & $20.7 \pm 0.47^{\mathrm{a}}$ & $23.3 \pm 0.62^{\mathrm{a}}$ & $79.8 \pm 2.15^{b}$ & $41.1 \pm 1.25^{\mathrm{b}}$ & $38.7 \pm 1.70^{\mathrm{cd}}$ \\
\hline & 10.0 & $20.8 \pm 0.61^{\mathrm{a}}$ & $21.2 \pm 0.82^{b}$ & $91.6 \pm 4.86^{\mathrm{a}}$ & $43.9 \pm 2.02^{\mathrm{ab}}$ & $47.6 \pm 3.04^{\mathrm{a}}$ \\
\hline
\end{tabular}

Means followed by the same letter are not significantly different $(P=0.05)$.

Chlorophyll as it is well known accumulates mainly in the mesophyll cells of the leaf. The quantitative changes observed in the increase of mesophyll thickness under MC treatment can be regarded as a feature providing increase of the leaf photosynthetic activity of plants. Thickening the epidermal tissues demonstrates the positive response of regenerants to $\mathrm{MC}$ application and can stimulate the plant resistance to adverse environmental conditions providing mechanical protection.

\section{Conclusions}

Thus, the thickness of the chlorophyll-bearing parenchyma and epidermal tissues of regenerant leaf blades of two $F$. ananassa cultivars is increased under MC treatment, which indicates the formation of plants characterized by a higher photosynthetic potential. The changes noted contribute to the further successful acclimatization of regenerants to ex vitro conditions. The results obtained on the application of MC based on biogenic silica and flavonoids of plant origin can be used for development of commercial systems for the production of $F$. ananassa improved planting material using biotechnological approaches.

In vitro propagation of $F$. ananassa microplants was carried out with the financial support of the budgetary project of the Central Siberian Botanical Garden, SB RAS No AAAA-A17-1170126100515 within the framework of the State Assignment. Anatomical analyses of plantlets were supported by the Russian Foundation for Basic Research and the Government of Novosibirsk Region as research project No 17-44-540339. In our study, in vitro material from the collection of the Central Siberian Botanical Garden SB RAS - USU 440534 "Collection of living plants indoors and outdoors" was used.

\section{References}

1. E.F. George, M.A. Hall, G.-J. De Klerk, Plant propagation by tissue culture (3rd Edition, Springer, 2008)

2. L. Argita, A. Gonzalez, R.S. Taméz, Physiologia Plantarum 115, 166-173 (2002).

3. F.T. Braga, C.F. Nunes, A.C. Favero, M. Pasqual, J.G. Carvalho, E.M. Castro, Pesqui Agropecu Bras 44, 128-132 (2009)

4. X. Yao, J. Chu, K. Cai, L. Liu, J. Shi, W. Geng, Biol. Trace Elem. Res. 43, 507-517 (2011)

5. O.I. Lomovsky, I.O. Lomovskiy, D.V. Orlov, Green Chemistry Letters and Reviews 4, 171-185 (2017) 
6. O.A. Rozhanskaya, O.I. Lomovsky, E.G. Trofimova, T.G. Lomova, Success mod. Sci. Educ. 8, 31-37 (2016)

7. E.V. Ambros, S.Y. Toluzakova, L.S. Shrainer, E.G. Trofimova, T.I. Novikova, In Vitro Cell. Dev. Biol. - Plant 54, 436-443 (2018)

8. E.G. Shapolova, Lomovsky O.I., Patent of Russian Federation, No. RU 2438344 C1, Byull. Izobret. 1 (2012) (in Russian)

9. O.L. Gamborg, D.E. Eveleigh, Can. J. Biochem. 46, 417-421 (1968)

10. E.M. Castro, F.J. Pereira, R. Paiva, Histologia vegetal: estrutura e função de órgãos vegetativos (UFLA, Lavras, 2009)

11. Y.M. Zhou, S.J. Han, Photosynthetica 43, 445-449 (2005)

12. K. Asada, Annu. Rev. Plant Physiol. Plant Mol. Biol. 50, 601-639 (1999)

13. A. Krieger-Liszkay Singlet, J. Exp. Bot. 56, 337-346 (2005)

14. S.A. Asmar, E.M. Castro, M. Pasqual, F.J. Pereira, J.D.R. Soares, Sci. Hortic. 161, 328$332(2013)$ 